\title{
Envisioning the atmospheric effect through (im)materiality
}

\author{
Nilay Ünsal Gülmez ${ }^{1}$, Dürnev Atılgan Yağan², Murat Şahin ${ }^{3}$, Efsun Ekenyazıcı Güney ${ }^{1}$, and \\ Hande Tulum ${ }^{1}$ \\ ${ }^{1}$ Bahçeşehir University, Department of Interior Architecture and Environmental Design, Istanbul, \\ Turkey \\ ${ }^{2}$ Bahçeşehir University, Department of Architecture, Istanbul, Turkey \\ ${ }^{3}$ Özyeğin University, Department of Architecture, Istanbul, Turkey
}

\begin{abstract}
In an attempt to bridge the gap between architectural/interior design practice and education, 'atmosphere' as a prolific contemporary architectural debate in practice and theory is covered by the experiment of 'Staging Poe' carried out as a first year Design Studio through the study of Edgar Allen Poe's selected poems. Poe's 1846 text of 'The Philosophy of Composition', unfolding his analytical method of writing and emphasis on "effect" in poetry, provides a ground for experimenting with facets of materiality and structuring the studio. Aiming to cultivate intuitive design experiments of students into informed processes in hybridizing conceptual/textual and material/sensual aspects, studio is structured in two phases. In the first phase, "materialization", idiosyncratic interpretations of students from words to materials with a focus on tectonic experiments and haptic experiences are sought in between materializing and dematerializing processes. In the second phase, the "atmospheric", emphasis on dematerialization of the perception of materials through tools, such as light, color and sound is exercised to transform the object into a performance stage. Outcomes of the studio on aspects pertaining to material and materialities in creation of the immaterial that is the atmosphere is followed and evaluated through responses of students' weekly reports.
\end{abstract}

\section{Introduction}

The concept of the atmosphere is very much on the agenda of contemporary architectural debates revolving around materiality and immateriality through projective theory [1,2]. Even though all attempts at re-sensualizing architecture, there are multiple approaches to presence and production of atmosphere in design disciplines. In professional practice, one can mention the literal inclusion of infrastructures making the immaterial air an atmospheric design element as in the case of Blur Building by Diller Scofidio + Renfro [2] and projects of Philippe Rahm [3] that can be traced back to the campfire phenomenon of Reyner Banham [4]. On the other hand, there is the condensation of sensorial aspects of space and materiality which gives room to haptic experience (tangibles) alongside all the other senses as in the works of Peter Zumthor, or immaterialization efforts through light, illusion, transparency and 
dissolving of the boundaries that can be observed in the works of Olafur Eliasson, Toyo Ito and SANAA with a special focus on vision and auditory senses (intangibles) [2].

However, within pedagogical contexts, it is possible to claim that such re-sensualizing attempts have not yet been incorporated enough into design education. Departing from the necessity of bridging the gap between architectural (more specifically interior) design practice, where atmospheric thinking is already influential, and design education, this paper covers the presentation of the process and outcomes of a project-based experimental study carried out in a first year Design Studio aimed at materializing/immaterializing the atmosphere of Edgar Allen Poe's selected poems. Poems; their verses and words are thought as conceptual appetizers for the making of atmospheres.

Two main questions will be debated in relation to the outcomes of this first-year studio experiment: First, how to think on the relationship between the conceptual/textual and the material/sensual through the concept of atmosphere and second, how to allow possible tools and opportunities to hybridize those seemingly opposing tenets while structuring the studio.

\section{Conceptual vs. Sensual or the Search for a Hybrid Becoming}

Relationship between the conceptual/textual and the material/sensual has always been and is still the main point of debate in architectural theory and in its epistemological origins. Immanuel Kant, as a key figure to differentiate the physical world as 'noumenal' and the world experienced as 'phenomenal', offers the possibility of understanding the object by a subject through experiences, unfolding how our bodily contact with the world and the conceptual thinking complement one another in explanation of knowledge [5]. Stretching from Kant to two "Peters" in 'Peter versus Peter: Eisenman and Zumthor's Theoretical Throwndown', A.J. Artemer (2016) presents the split in contemporary architectural scene, diagnosing a battle between Zumthor, and Eisenman as '... between phenomenology and autonomy, emotion and rationality, between materiality and concept, and being in the world and transcending it', respectively [6]. Meanwhile, Antoine Picon points out to a materiality as a hybrid between seemingly opposing categories of abstract and concrete in the age of computer [7]. At present, a paradigm shift to reinstate the authority of making (praxis) in design and to find alternative ways to heal the split between thinking and making like integration of architecture/design with visual arts and performing arts is creating an transdisciplinary platform that can be observed in a multitude of current debates on the concept of atmosphere and its various understandings in relation to aesthetics [8,9], embodied spatial experience [10], politics [11] and philosophy [12].

\section{Unfolding Materiality}

The education of architecture and design also took its share from the split between the conceptual and the sensual, the mind and matter. The importance given to unveil the already given information in the world waiting to be decoded with extensive analysis on one hand, versus the belief in subjective creative talent of the designer, the idea of genius on the other have been influential in structuring the design schools and their curriculums. Moreover, from the day education is liberated from the material world - when the act of thinking/ideas considered superior to act making - onwards the education has long been dependent of immaterial presentation of thoughts, the drawings [13]. The Bauhaus school has reminded the significance of 'making' with its emphasis on ateliers and craftsmanship and acted as a melting pot for opposing tenets in its ambitious intend to bring art and crafts, the subject and 
object, the mind and world together [14]. The technology now is hybridizing thinking with producing, reorienting them as simultaneous acts and facilitating the way thoughts are materialized in virtual or actual environments. Due to the zeitgeist of the era, design schools are welcoming technologically apt students and curriculums are to transform accordingly.

We argue that all the process of atmospheric creation could be regarded as a constant dialogue between facets of materiality (material, immaterial and non-material) and this dialogue shall be incorporated into the education of design disciplines from the very beginning. Yet, this requires unfolding the term 'materiality' to reveal it potentials in cultivating design education.

Pointing out to a change in understanding of materiality from the past to present, Gernot Böhme [14], expresses the change from an idea of integrity and inconspicuousness of materials; into one where 'materiality is to show itself, to come forward, to help shape the atmospheres'. Referring to the valeurs d'ambiance of Baudriallard, Böhme proposes the term 'theatrical value' in describing the new understanding of materiality and its role in formation of character of space that oriented towards 'staging materiality'[15]. He defines three types of relationship with the materials: work-related, perceptual and the medial. The work-related relationship is about the way we deal and experiment with the raw material, the way we search for its nature even force or change it to an extent. In the perceptual relationship, we are involved with the manifestations of materiality, 'the pure form of its appearance' that includes dimensions of physiognomy, its synesthetic and social character. The third one, medial relationship is experiential. Referring to Aristo, Böhme defines it as sensing the environment we exist with our flesh physically that is about to 'remain bodies among other bodies and live within the media'. This is more about the memory of our flesh, rather than touching [16].

The new understanding of materiality embraces both the physical substance of material itself and all the immaterial aspects like (light, sound, water vapor) that add theatrical value to the materials themselves by concealing, augmenting or changing/transforming physical and perceivable features of materials. This broader conception of materiality also helps in rethinking space as a performative domain, a container (void) setting the stage for ephemeral becoming. At the end, all contribute to a (creation of) non-material issue, the spirit of place (the genius loci) described as 'ephemeral and unfocused' related to 'its unique perceptual and memorable character' by Juhani Pallasmaa [17] that approximates to the definition of atmosphere. Such a definition, the feeling emanating from the character of place/space highlights its 'effect' on the viewer/perceiver and refers to the third definition of materiality by Böhme, the medial and experiential one.

Unfolding materiality, the emergence of new tropes in current architectural discourse in tandem with the pace of technology like 'material responsiveness', 'trans-materiality' and 'dematerialization', also helps interacting and approximating the scientific/objective facts with artistic/subjective imagination [18]. Sandra Karina Löschke uses the term 'immaterial materiality' to express the immediate effect of such an understanding of materiality on the process of design of objects to be conceived as "not constructed to satisfy aspects of monumentality, formal style or functionality, but to generate a multitude of temporal perfections and effects' [19]. Dematerialization in its reference to the process, is about an addition of ineffable elements that dissolves the appearance or perception of physical substance of the materials, their character. Toyo Ito's use of daylight and artificial light adding lightness to his buildings pushing them to the edge of dematerialization [20], or SANAA's play with light and translucency creating layers of cloudy surfaces and shadowy silhouettes in space epitomize such practices in architecture. 


\section{Bridging the Gap in the Beginnings of Design Education}

Recently, there has been an increasing tendency towards bringing sensuous aspects of design and related tools forward in the first-year studios. However, the atmospheric issues that we suggest as appropriate in first year design studios to bridge the gap between the mind and the matter; and to unfold the concept of materiality embracing all its components be it material, quasi-material and immaterial have not been widely incorporated into design education. The efforts encountered in the literature so far are mostly addressing senior students such as John Stanislaw Sadar's [21] redesign of an environmental technology coursework to work with atmospheric energies; Gerlinde Verhaeghe's [22] 'mixed media atlas' that challenge' the split between idea and the material' and Sandra Löschke and Michael Day's [23] Coproductions graduate studio that focused on the interplay between material, light and space.

Cultivating the intuitive elements pertaining to materials and materialities embedded in the already existing experience of anybody, a group of first-year interior design students, in our case, is mediated through the study of atmospheres, that is another embedded experience. Böhme uncovers this embedded experience as a dominant relationship with materials starting from early childhood that operates in the "background memory" and calls it "the medial' [24]. In studying an immaterial phenomenon that is the atmosphere, the medial experience of students is to be unfolded through to bring out the role of material and materiality into a conscious and informed design process and experimentation for the students.

We argue that, for novice design students, beginning with narratives, some literary texts and/or cult authors/poets they are familiar with might provide a potential for the creation of (im)material constructs that speak to the senses and could be taken as a starting point to bridge the gap between the conceptual and material. For our case, Edgar Allen Poe has been introduced as a key figure to contemplate on the mystery of the beginnings. Anthony C. Antoniades [25], who underlines the fertility of the involvement of "obscure angles" utilized by many arts, such as poetry, literature, music and film, also points to Edgar Allen Poe's techniques of atmosphere and mood creation in prose and poetry to stimulate experiments in design education. Poe and his emphasis on 'effect' in poetry emanating from the 'atmosphere' provided a ground for experimenting with facets of materiality in multiple varieties.

After a thorough analysis of his anthology, five poems having strong spatial atmospheric tones, namely The Valley of Unrest, The City in the Sea, Dream-land, Fairyland, and Silence Sonnet are selected to be envisioned and staged by the students. Poe's seminal text 'The Philosophy of Composition' [26], where he unfolds how he wrote - his famous poem - 'The Raven', has been influential in choosing his poems and structuring the experiment 'Staging Poe': Firstly, through the manifestation of his analytical method of writing with a mathematical precision proceeding step by step to the final goal of transferring the intended 'effect' which contradicts with the so-called assumption that he wrote these romantic poems intuitively; Secondly, through the exploration behind transformation of the raven, main character of his famous poem, the narration of which is established upon its reality, into the metaphor of pain and remembrance that made us contemplate on transitions from the abstract to material and immaterial respectively and their cyclical presence. 


\section{Staging Poe}

The proposed approach for translation of literary effect into a spatial atmosphere/ambiance in the studio is composed of sequential yet cyclical steps that could be mainly discussed in two phases: First, the materialization phase in the search for idiosyncratic translations of students from words to materials with a specific focus on tectonic experiments and haptic experiences oscillating between materializing and dematerializing (forcing the limits of materials or transforming their nature by hybridization processes); second, the atmospheric phase, making use of light and sound to dematerialize the appearance of materials used that accompanies the ongoing tectonic experiments (figure 1).

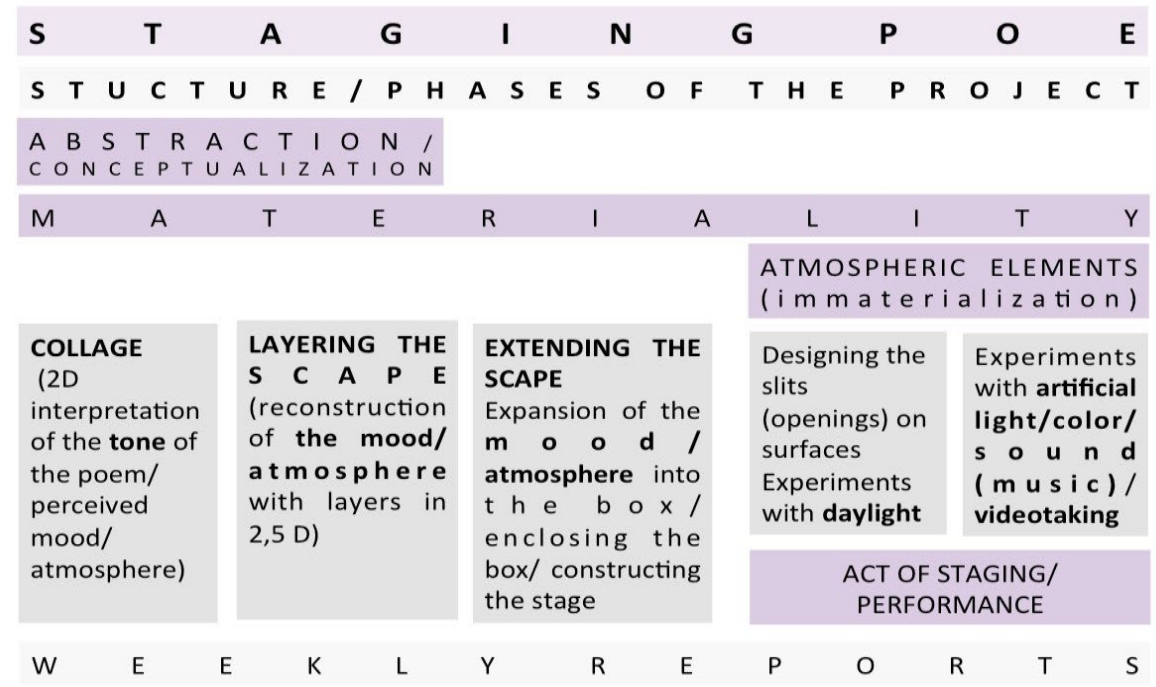

Fig. 1. The Flow of the Project 'Staging Poe'.

The materialization phase starts with (a) collage making and (b) layering the scape that foster students to contemplate on the tone of the poem and their personal response while thinking on abstraction in translating the perceived mood/atmosphere into materials, beginning from two dimensional to gradually develop into the third in the following one, that is (c) extending the scape into a boxy frame. This step paves the way for tectonic experiments that make students get acquainted with the nature of materials, compel their possibilities to the limits and recognize the character of materials. Formal searches for articulating and sequencing elements appear as integral part of material and structural experiments. The material phase concludes with (d) enclosing the frame of the box and opening a peek-hole to be able to have visual access to the interior. Once the frame is enclosed, it leaves the body of the student out limiting the experience of proximate senses, specifically haptic experience of the atmospheric field within.

Overlapping with the materialization phase to some extent, the atmospheric phase begins with (e) opening slits on the surfaces of the box (f) to experiment with daylight, artificial colored-light and with multiple sources of light consecutively (figure 2). The position and amount of slits are repeatedly articulated with respect to the light experiments in search for capturing the imagined atmosphere. This step is followed by (g) the selection of a music piece 
by the students that would enhance the intended atmosphere inside the box. Light, color and sound act as ephemeral dematerializing agents transforming the whole box-space into a 'theatre stage'.

In order to understand the mutual and sometimes tense relationship between materialization and dematerialization processes and to conceive the ephemeral quality of immaterial atmospheric agents, unconventional tools have also been utilized in the studio. Considering the box as atmosphere/ambiance generator, the students have recorded multiple performances under changing conditions of light and sound/music. Selections of music have been observed to be very much related to the rhythm of their camera moves and envisioned atmosphere of the stage. Affirming Pallasmaa [27], music pieces helped creating 'lived and existential atmospheric interior spaces, ephemeral and dynamic experiential fields'. In its resemblance to the experience of dioramas, students experimented and assessed the atmospheres/ambiances generated in viewing inside of the boxes through the peephole under constantly changing conditions. At the final stage, short videos are taken by the students and shared via a social networking app (\#stagingpoe2018) to open up the atmospheric performance of the closed mysterious box to the viewing and comments of all studio participants (figure 3).
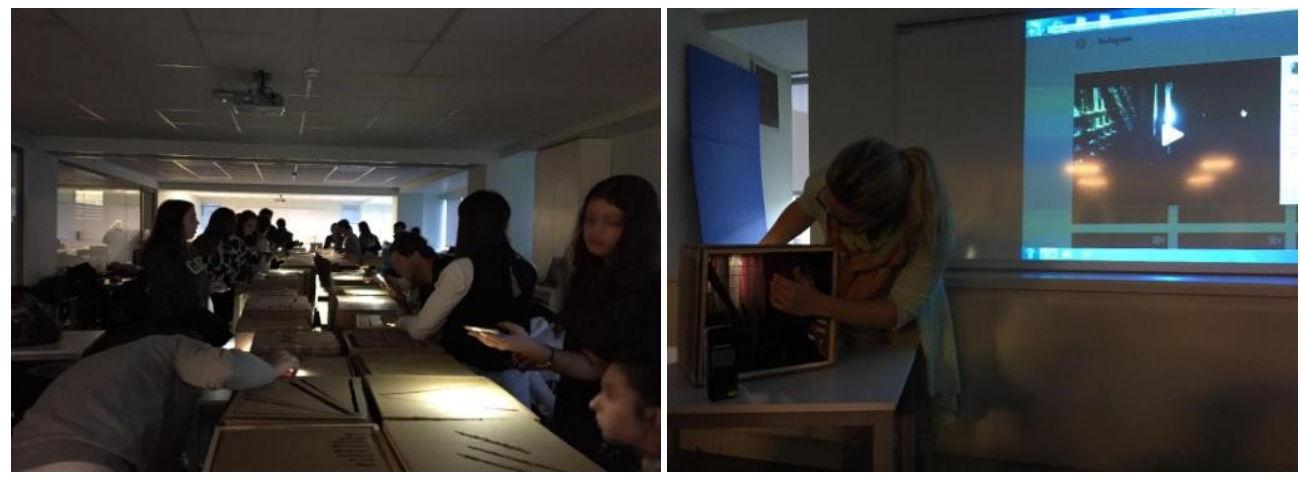

Fig. 2. (left). Students experiencing the atmospheres inside the boxes under changing light conditions

Fig. 3. (right). Final presentation of project 'Staging Poe', the box and the video.

\section{Discussion}

In this project, referring to Böhme's types of relationship with the materials, all three (making, perceptual and medial) have been experienced by students in sequential phases: First, in recognizing the nature of materials by making, then by observing the change in appearance of materials after enclosing the box and structuring the light experiments, and lastly by uncovering their embedded relationship with materials and associated memories that have been operational in their material choices and making decisions.

During the process, students were asked to write online weekly-reports where they replied to questions regarding the process. Writing is instrumentalized as a pedagogical tool that aimed at initiating a dialogue between how students think and make. The act of writing through the process also made a subtle reference to the literary pieces that have been used as appetizers at the beginning. We observed that, starting with the effect of Poe's poems, experimenting with facets of materiality in search for staging the atmosphere of the poems by intuitive use of material-immaterial agents and incorporation of dematerializing processes, 
culminating with videos that present the ephemeral, transient nature of the atmospheres have provided a holistic introduction and understanding on both the nature and processes of design.

The reports revealed that most of the students associated the mood of the poems with the character of the materials. The perceptions regarding the character of materials were idiosyncratic that can be related with students' medial relationship with materials. Many students started considering and working with the texture and surface quality of materials (transparency, translucency, porosity) according their performance under atmospheric agents. They achieved awareness about the facets of materiality (material, immaterial and nonmaterial) and their role in creation of the ephemeral, performative atmospheres.

\section{References}

1. R. Somol, S. Whiting. 'Notes around the Doppler Effect and Other Moods of Modernism', in Constructing a New Agenda: Architectural Theory 1993-2009. A. K. Sykes (ed.), New York: Princeton Architectural Press (2010)

2. O. W. Fisher. Atmospheres-Architectural Spaces between Critical Reading and Immersive Presence, Field, 1, (1), pp. 24-41 (2007)

3. http://www.philipperahm.com/data/index.html (accessed: 01.02.2019)

4. R. Banham. 'A Home is not a House' in Housing and Dwelling. Perspectives on Modern Domestic Architecture, B. Miller Lane (ed.), London and New York: Routledge, pp. 54-60 (2007)

5. M. Gelertner. Sources of Architectural Form. A Critical History of Western Design Theory. Manchester and New York: Manchester University Press, p.177 (1995)

6. AJ. Artemer. https://architizer.com/blog/practice/tools/peter-versus-peter/ (accessed: 29.01.2018)

7. A. Picon. "Architecture and the Virtual: Towards a New Materiality" in Constructing a New Agenda. Architectural Theory 1993-2009. A. K. Skyes (ed.), New York: Princeton Architectural Press. p. 282 (2010)

8. G. Böhme. The Aesthetics of Atmospheres. Ambiances, Atmosphrese and Sensory Experiences of Spaces, J. P. Thibaud (ed.), London and New York: Routledge, pp.144145. (2017)

9. T. Grifero. Quasi-things: The paradigm of atmospheres. New York: State University of New York. (2017)

10. P. Zumthor. Atmospheres. Basel: Birkhäuser. (2006)

11. C. Borch. Architectural Atmospheres. On the Experience and Politics of Architecture. Basel: Birkhauser. (2014)

12. P. Sloterdijk. Foams: Spheres Volume III, Plural Spherology, Los Angeles: Semiotext(e). (2016)

13. J. Hill. 'Hunting the shadow-immaterial architecture', The Journal of Architecture, 8 (2), pp. 165-179. (2003)

14. Gelertner. Sources of Architectural Form. pp.238-250

15. Böhme. The Aesthetics of Atmospheres, p.143

16. Ibid, p. 147

17. J. Pallasmaa. 'Space, Place and Atmosphere: Peripheral Perception in Existential Experience' (pp. 18-41) in Architectural Atmospheres on the Experience and Politics of Architecture, C. Borch (ed.), Basel: Birkhauser, p.20. (2014)

18. S. K. Löschke. 'Immaterial materialities: Aspects of materiality and interactivity in art and architecture' in Interstices 14, Journal of Architecture and Related Arts, (pp. 5 11) p. 5 
19. https://www.interstices.ac.nz/published-journals/interstices-14-immaterialmaterialities/ (accessed 01.02.2019). (2013)

20. Löschke. Immaterial materialities, p. 6

21. S. Allen. 'Toyo Ito's Patient Search' In Toyo Ito: Forces of Nature (ed. Jessie Turnbull), New York: Princeton Architectural Press. p.22. (2012)

22. J. S. Sadar. Quasi-Materials and the Making of Interior Atmospheres. Interiority, 2018, 1, (1), pp. 49-63. (2018)

23. G. Verhaeghe. 'Learning Architectural Design. Material and Immaterial Aspects' Design for Next, $12^{\text {th }}$ EAD Conference, Sapienza University of Rome, pp. 12-14 (2017) 24. S. Löschke, S. and M. Day. Co-Productions: Material Light Architecture Studio (https://www.uts.edu.au/sites/default/files/UTS-dab-ug-2014.pdf)(accessed 01.02.2019) 25. G. Böhme. The Aesthetics of Atmospheres, p.147

26. A. C. Antoniades. Poetics of Architecture: Theory of Design. New York: Van Nostrand Reinhold. p. 99. (1990)

27. E. A. Poe. The Philosophy of Composition, CreateSpace Independent Publishing Platform (first published in 1846). (2015)

28. J. Pallasmaa. 'Space, Place and Atmosphere: Peripheral Perception in Existential Experience' (pp. 18-41) in Architectural Atmospheres on the Experience and Politics of Architecture, C. Borch (ed.), Basel: Birkhauser. (2014) 